\title{
The effects of different degrees of head-of-bed elevation on the respiratory pattern and drainage following thyroidectomy: a randomized controlled trial
}

\author{
Serpil Yüksel ${ }^{1}$, Seher Deniz Öztekin ${ }^{2}$, Zeynep Temiz ${ }^{3}$, Gülay Altun Uğraşs ${ }^{4}$ Emel Şengül ${ }^{5}$, \\ Serkan Teksöz ${ }^{5}$, Nihal Sunal ${ }^{6}$, İlhan Öztekin ${ }^{7}$, Ertuğrul Göksoy ${ }^{5}$
}

1. Necmettin Erbakan University, Faculty of Nursing, Department of Surgical Nursing, Konya, Turkey. Office phone: +903323204049 (2029 ext.)

2. Istanbul University-Cerrahpaşa, Florence Nightingale Faculty of Nursing, Department of Surgical Nursing, İstanbul, Turkey. Office phone: +902124400000 (27014 ext.)

3. Artvin Çoruh University, Faculty of Health Science, Division of Nursing, Department of Surgical Nursing, Artvin, Turkey. Office phone: +904662151000 (2134 ext.)

4. Mersin University, Faculty of Nursing, Department of Surgical Nursing, Mersin, Turkey. Office phone: +903243610581(4221 ext.

5. Istanbul University-Cerrahpaşa, Cerrahpaşa Faculty of Medicine, Department of General Surgery, İstanbul, Turkey. Office phone: +902124143000

6. Istanbul Medipol University, Faculty of Health Science, Division of Nursing, İstanbul, Turkey. Office phone: $+902125317555$

7. Yeditepe University Hospital, Department of Algology, İstanbul, Turkey. Office phone: +905326835539

Emails:

yukselserpi11977@gmail.com; oztekin.deniz@gmail.com; erzeynep_@hotmail.co.uk; carpediem0803@yahoo.com; emel. sengul@hotmail.com/serkanteksoz@gmail.com; nsunal@medipol.edu.tr; info@ilhanoztekin.com/goksoy@istanbul.edu.tr

\begin{abstract}
Background: The patient's position is important for ensuring patient comfort and preventing complications after thyroidectomy.

Objectives: This study was carried out to determine the effects of different degrees of head-of-bed elevation (HOBE) on the respiratory pattern and drainage following thyroidectomy and to provide suggestions for evidence-based clinical practice.

Methods: The sample of this prospective, parallel arm, randomized controlled trial included 114 patients undergoing thyroidectomy in a university hospital in Turkey. The patients were randomly assigned (1:1:1) to supine $0^{\circ}$ (baseline), $30^{\circ}$ and $45^{\circ} \mathrm{HOBE}$ groups. Respiratory pattern including respiratory rate (RR), peripheral oxygen saturation $\left(\mathrm{SpO}_{2}\right)$ and dyspnea, and

drainage including amount of drainage and hematoma formation were evaluated at the $1^{\text {st }}, 2^{\text {nd }}, 3^{\text {td }}$ and $4^{\text {th }}$ hours following thyroidectomy.

Results: The majority of the patients $(83.3 \%)$ were female and $84.2 \%$ had undergone total thyroidectomy. The mean RR (18.47, $95 \% \mathrm{CI}=17.85-19.09$ ) of the patients in the supine $30^{\circ} \mathrm{HOBE}$ group at the $1^{\text {st }}$ hour was significantly higher than that of the patients in the supine $0^{\circ}$ group $(17.32,95 \% \mathrm{CI}=16.88-17.76$; $\mathrm{p}<0.05)$. There was no significant difference between the

$\mathrm{SpO}_{2}$ values of the patients in the groups $(\mathrm{p}>0.05)$. The amount of drainage was significantly higher in the supine $0^{\circ}$ group at the 2 nd hour than that of the patients in the supine $45^{\circ} \mathrm{HOBE}$ group $(5.92 \pm 5.18 ; 3.34 \pm 5.56$ respectively; $\mathrm{p}<0.05)$. None of the patients in the groups had hematoma formation. While no patient in the supine $30^{\circ} \mathrm{HOBE}$ group had dyspnea, dyspnea occurred in 9 patients in the supine $0^{\circ}$ group and in 3 patients in the supine $45^{\circ} \mathrm{HOBE}$ group.

Conclusion: This study showed that different HOBE positions resulted in clinically insignificant changes on the RR and amount of drainage during the first 4 hours following thyroidectomy but did not affect $\mathrm{SpO}_{2}$ value.

Keywords: Head-of-bed elevation, thyroidectomy, controlled trial.

DOI: https://dx.doi.org/10.4314/ahs.v20i1.55

Cite as: Yüksel S, Öztekin SD, Temiz Z, Uğras GA, Şengül E, Teksöz S, et al. The effects of different degrees of head-of-bed elevation on the respiratory pattern and drainage following thyroidectomy: a randomized controlled trial. Afri Health Sci. 2020;20(1):488-97. https://dx.doi. org/10.4314/abs.v20i1.55
\end{abstract}

Corresponding author:
Serpil Yüksel,
Necmettin Erbakan University, Faculty of Nursing,
Department of Surgical Nursing, Konya/Turkey.
Mobile phone: +905052933760; Office phone:
+903323204049 (2029 ext.); Office fax: +903323204059
E-mail: yukselserpil1977@gmail.com

\section{Corresponding author:}

Serpil Yüksel,

Necmettin Erbakan University, Faculty of Nursing,

Department of Surgical Nursing, Konya/Turkey.

+903323204049 (2029 ext.); Office fax: +903323204059

E-mail: yukselserpil1977@gmail.com

\section{Introduction}

Thyroidectomy is a safe surgical procedure commonly used for the treatment of benign or malignant tumors, multinodular goiter and Graves disease. ${ }^{1-3}$ However, because of the rich vascular structure of the thyroid gland, serious complications including hemorrhage, 
hematoma and hematoma-related dyspnea can develop after thyroidectomy. ${ }^{1,-6}$

There are many studies in the literature addressing the causes, preventive interventions and treatment of complications such as hemorrhage, hematoma and respiratory problems in patients after thyroidectomy. ${ }^{4,7-13}$ Some of these studies investigated the effects of positions such as semi-Fowler's position, beach chair, partial trendelenburg or flat supine and valsalva maneuver on bleeding control and prevention of hematoma. ${ }^{10-12} \mathrm{~A}$ previous study showed that patients should be placed in a semi-Fowler's position to achieve bleeding control after thyroidectomy, however, but it did not examine efficacy of position on bleeding control. ${ }^{10} \mathrm{~A}$ review suggested that the head of bed should be elevated at 3045 degrees after thyroidectomy in order to prevent the formation of airway obstruction in the patient caused by laryngeal edema due to surgical manipulation. ${ }^{14}$ The American Thyroid Association also recommended to keep the patient in a head-up at $45^{\circ}$-Fowler's position in the post anesthesia care unit following thyroidectomy to prevent hematoma formation on the incision site by facilitating venous return from the head and neck. ${ }^{11}$ The mentioned guideline does not offer any recommendations regarding the position that should be given to the patients at surgical clinic after thyroidectomy.

As the position of the body affects oxygenation, ${ }^{15,16,17}$ hemodynamics such as heart rate, systolic and diastolic blood pressure, ${ }^{15,18}$ the effect of the position given to patients is important. In the early period following thyroidectomy, patients are given supine $0^{\circ}$ (especially those with low blood pressure), $30^{\circ}$ and $45^{\circ} \mathrm{HOBE}$ positions in surgical care units, but there are currently no research findings on the effect of these positions on patients with thyroidectomy. The existing studies about these positions showed that supine position decreases systolic blood pressure in hypertensive individuals ${ }^{17}$ and decreases lung function in healthy adults, ${ }^{19,20}$ abdominal surgical patients, ${ }^{17}$ and cardiac surgery patients undergoing mechanical ventilation $(\mathrm{MV})^{16}$ and that $30^{\circ}$ and $45^{\circ} \mathrm{HOBE}$ positions improves lung function. In a similar study, it was determined that supine position reduced breathing frequency. ${ }^{21}$

Following thyroidectomy, giving the appropriate position to the patient by the nurse and closely monitoring the patient's breathing and amount of drainage are important for early detection of complications such as bleeding and breathing problems. ${ }^{14,22}$ Therefore, this study aimed to identify the effects of different degrees of HOBE on respiratory pattern and drainage of patients following thyroidectomy, and to provide evidence-based suggestions for nurses.

\section{Methods \\ Study design and setting}

This study was conducted as a prospective, single-center, parallel, three arm [1:1:1], randomized controlled trial at the Endocrine Surgery Clinic of a university hospital in Istanbul, Turkey between May 1, and September 30, 2013. Located in Istanbul, the largest city in Turkey, the Endocrine Surgery Clinic, where the study was conducted, is a center where patients with thyroid, parathyroid and adrenal glands disorders from many parts of Turkey seek treatment. On a monthly average, 40 thyroidectomy operations are performed in this center with 19 beds.

This trial was registered with ClinicalTrials.gov (ID NCT03816371) and approved by the Istanbul University Cerrahpaşa Medicine Faculty Clinical Researches Ethics Committee (Number/date: 3029/2013). The participants were informed that their participation was based on voluntariness before surgery. Finally, written and oral permissions were obtained from all the patients who participated in the study.

\section{Participants}

The study population consisted of 150 patients aged 18 years and older who underwent total thyroidectomy at the Endocrine Surgery Clinic between May 1, and September 30, 2013.

None of the patients had any mental disorder that interfered with communication. The eligible participants were those who were not using anticoagulants, whose coagulation tests were normal, who had hemovac drains inserted during thyroidectomy, who had no contraindication to positioning (e.g., heart failure, chronic obstructive pulmonary disease, dyspnea before surgery and respiratory complications in the post-anesthesia care unit), who could tolerate positioning, and who volunteered to participate and signed the informed consent form. The participants who were using anticoagulants, whose coagulation tests were abnormal, who had hemovac drains inserted during thyroidectomy, who had hemovac drains removed in the post-anesthesia care unit following thyroidectomy, who did not tolerate positioning and who refused to participate were excluded from the study (Figure 1). 


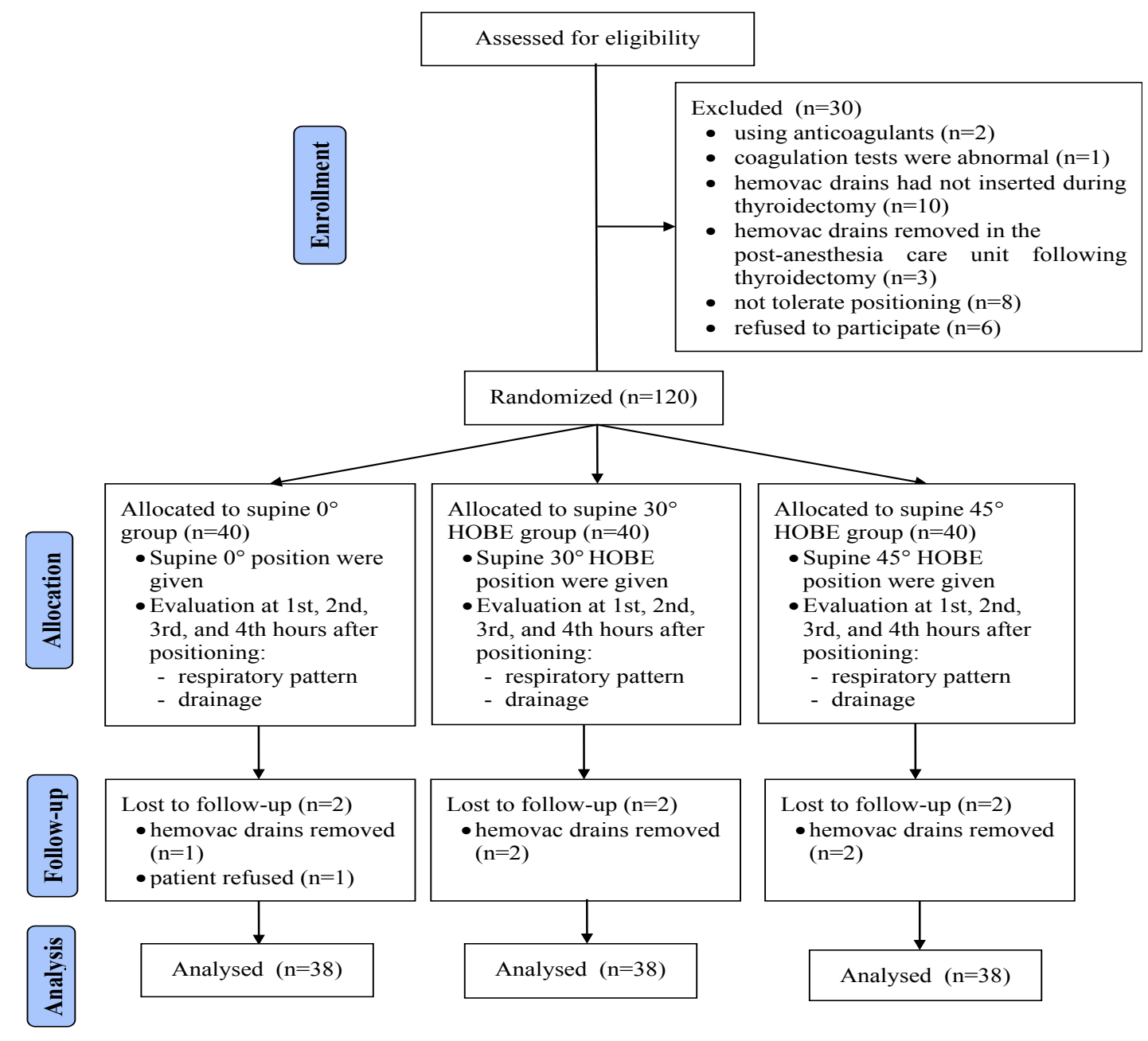

HOBE: head-of-bed elevation

Figure 1: CONSORT flow diagram for this trial

All the patients were evaluated before and after thyroidectomy in terms of the inclusion and exclusion criteria by the two surgeons and one anesthesia physician in the study, who were not aware of which participant had been assigned to which group. As a result of this evaluation, 30 patients were excluded from the study. Also, five patients who had hemovac drains removed and one patient who refused the position were excluded from the study during the follow-up (Figure 1).

\section{Procedures}

The eligible patients transferred to the ward from the operating theatre following thyroidectomy were randomly assigned to the experimental groups (supine $30^{\circ}$ HOBE and supine $45^{\circ} \mathrm{HOBE}$ ) and the control group (baseline: supine $0^{\circ}$ group) by the clinical nurse in the study. The degree of HOBE was arranged by the same nurse as soon as the patient was admitted to the bed. The HOBE degrees were measured using goniometer.
Data concerning the patients' socio-demographic and clinical characteristics were collected using a data collection form developed based on the relevant literature $^{8-10,14,15,22-26}$ by the researchers.

Respiratory pattern including respiratory rate (RR), peripheral oxygen saturation $\left(\mathrm{SpO}_{2}\right)$ and dyspnea, and drainage including amount of drainage and hematoma formation of all patients were evaluated at $1^{\text {st }}, 2^{\text {nd }}, 3^{\text {rd }}$, and 4th hours (Figure 1).

No patient required termination from the study due to adverse events associated with positions.

\section{Outcome measures}

The primary outcome measures of this study were RR, $\mathrm{SpO}_{2}$, and amount of drainage.

Respiration rate was counted for one minute ${ }^{27}$ by the clinical nurse in the study. $\mathrm{SpO}_{2}$ was measured with pulse oximeter (Covidien nellcor-08787, Kalimed Medikal, Ankara, Turkey) and the amount of drainage in the hemovac drain suction bottle was recorded by the clinical nurse in the study. The amount of drainage was 
used to evaluate postoperative hemorrhage $(\mathrm{POH})$. The symptoms including red drainage, bleeding from incision and the accumulation of more than $150 \mathrm{ml}$ per hour drainage in the suction bottle were defined as POH. ${ }^{9,26}$

The secondary outcome measures of this study were dyspnea and hematoma formation.

Dyspnea is defined as "a subjective experience by individuals who complain of unpleasant or uncomfortable respiratory sensations" in the consensus statement published by the American Thoracic Society in $1999 .{ }^{28}$ Dyspnea was evaluated by the anesthesia physician in the study.

In this study, hematoma formation was evaluated by the surgeons in the study by monitoring warning signs such as progressive neck swelling, hypoxia, tachycardia, dyspnea and stridor. ${ }^{10,11}$

\section{Sample size}

The effect size of the difference between the means of $\mathrm{RR}, \mathrm{SpO}_{2}$ and the amount of drainage to be obtained from the four repeated measures according to the three different positions (i.e., supine $0^{\circ}$, supine $30^{\circ}$ $\mathrm{HOBE}$ and supine $45^{\circ} \mathrm{HOBE}$ ) would be at least 0.25 (i.e., medium impact for variance test) with a two-sided type I (alpha) error rate of 0.05 and 80\% power, the calculations performed in $G^{*}$ Power program showed that each of the groups should have at least 38 people (37.7) and there should be a total of 113 people. The study was completed with 114 patients.

\section{Randomization and masking}

The consenting, eligible patients were randomly assigned to the experimental groups or the control group according to their arrival sequence in blocks of three in a 1:1:1 ratio using the block randomization method. The randomization sequence was developed using a computer-generated table of random groups by a biostatistician who was not associated with the study.

Group allocation was concealed using individual sealed opaque envelopes that were numbered in sequential order. As individuals were enrolled in the study, the next envelope in the sequence was extracted and the participant was assigned to the groups accordingly. When the patient was transferred from the operating theatre to the ward, the clinical nurse in the study assigned the patient to one of the groups according to the list in the envelope and gave the corresponding position. All the researchers except for the clinical nurse who positioned the patients according to randomization list and patients were blinded from group assignment.

\section{Data analysis}

Continuous data were described using mean, standard deviation, and 95\% confidence interval (CI) values, and categorical variables were analyzed using frequency and percentage. In the analysis of the data on the amount of drainage, the median and the first and third quartiles were given. Pearson's Chi-square test and one-way ANOVA were used to compare the similarity of the groups in terms of their baseline characteristics.

Also, parametric tests were used according to the Central Limit Theorem in the analysis of continuous data (RR and $\mathrm{SpO}_{2}$ values). ${ }^{29}$ Whether there was a difference in $\mathrm{RR}$ and $\mathrm{SpO}_{2}$ between the groups was evaluated using the one-way ANOVA and post hoc test (Tukey HSD test). The repeated measures ANOVA and post hoc test (Bonferroni analysis) were used to determine the time-dependent change of $\mathrm{RR}$ and $\mathrm{SpO}_{2}$ values measured at different times within the group.

Due to the presence of " 0 ", which is show that no drainage in drainage data, the type of drainage measure were accepted as ordinal rather than ratio and nonparametric tests were used in the analysis of drainage data. Kruskal Wallis $\mathrm{H}$ test and post hoc test (Dunn) were used to determine whether there was a difference in the amount of drainage between the groups. Friedman's 2-way test by ranks was used to determine the time- dependent change of the amount of drainage measured at different times within the group.

As there were few patients with dyspnea, no statistical evaluation could be performed between the groups. McNemar chi-square test statistic was used to determine the change in dyspnea formation within the group at different evaluation times. Data were presented using graphs.

The two side type 1 error rate was accepted maximum $5 \%$. Statistical analyses were performed using E-picos software (www.e-picos.com, NY, New York) and MedCalc Statistical Software version 16.4.3 (MedCalc Software bvba, Ostend, Belgium; https://www.medcalc. org; 2016).

\section{Results}

\section{Descriptive characteristics of patients}

The study was completed with 114 patients (Figure 1). The mean age of the patients was 46.61 years $(\mathrm{SD}=15.26)$, most of them were female $(83.3 \%)$ and $36 \%$ were overweight. More than half of the patients $(69.3 \%)$ had a diagnosis of multinodular goiter. Most of the patients $(84.2 \%)$ underwent total thyroidectomy. The mean surgical intervention time of the patients was 58.46 minutes $(\mathrm{SD}=25.85)$ (Table 1$)$.

African Health Sciences Vol 20 Issue 1, March, 2020 


\begin{tabular}{|c|c|c|c|c|c|}
\hline Characteristics & Total & $\begin{array}{c}\text { Supine } 0^{\circ} \\
\text { Group }^{1} \\
(\mathrm{n}=38)\end{array}$ & $\begin{array}{c}\text { Groups } \\
\text { Supine 30 } \\
\text { HOBE } \\
\text { Group }^{2} \\
(\mathrm{n}=38) \\
\end{array}$ & $\begin{array}{c}\text { Supine } 45^{\circ} \\
\text { HOBE } \\
\text { Group }^{3} \\
(\mathrm{n}=38)\end{array}$ & Test/p \\
\hline Age, y, mean (SD) & $46.61(15.26)$ & $44.82 \pm 14.93$ & $48.42 \pm 16.61$ & $46.58 \pm 14.33$ & $0.526 / 0.59^{*}$ \\
\hline \multicolumn{5}{|l|}{ Gender, $\mathrm{n}(\%)$} & \multirow[b]{2}{*}{$0.505 / 0.78^{\psi}$} \\
\hline $\begin{array}{l}\text { Female } \\
\text { Male }\end{array}$ & $\begin{array}{l}95(83.3) \\
19(16.7)\end{array}$ & $\begin{array}{l}31(81.6) \\
7(18.4)\end{array}$ & $\begin{array}{l}31(81.6) \\
7(18.4)\end{array}$ & $\begin{array}{c}33(86.8) \\
5(13.2)\end{array}$ & \\
\hline \multicolumn{5}{|c|}{ Body mass index, $\left(\mathrm{kg} / \mathrm{m}^{2}\right) \mathrm{n}(\%)$} & \multirow[b]{2}{*}{$1.087 / 0.90^{\psi}$} \\
\hline $\begin{array}{l}\text { Normal (18.5-24.99) } \\
\text { Overweight }(25.0-29.99) \\
\text { Obese }(\geq 30)\end{array}$ & $\begin{array}{l}38(33.3) \\
41(36.0) \\
35(30.7) \\
\end{array}$ & $\begin{array}{l}13(34.2) \\
13(34.2) \\
12(31.6) \\
\end{array}$ & $\begin{array}{l}12(31.6) \\
16(42.1) \\
10(26.3) \\
\end{array}$ & $\begin{array}{l}13(34.2) \\
12(31.6) \\
13(34.2) \\
\end{array}$ & \\
\hline \multicolumn{5}{|l|}{ Diagnosis, n (\%) } & \multirow[b]{2}{*}{$3.313 / 0.51^{\psi}$} \\
\hline $\begin{array}{l}\text { Multinodular goiter } \\
\text { Graves' disease } \\
\text { Thyroid cancer }\end{array}$ & $\begin{array}{l}79(69.3) \\
10(8.8) \\
25(21.9) \\
\end{array}$ & $\begin{array}{c}28(73.7) \\
3(7.9) \\
7(18.4) \\
\end{array}$ & $\begin{array}{l}28(73.7) \\
4(10.5) \\
6(15.8) \\
\end{array}$ & $\begin{aligned} & 23(60.5) \\
& 3(7.9) \\
& 12(31.6) \\
&\end{aligned}$ & \\
\hline \multicolumn{5}{|c|}{ Type of thyroidectomy, $\mathbf{n}(\%)$} & \multirow[b]{2}{*}{$2.771 / 0.25^{\psi}$} \\
\hline $\begin{array}{l}\text { Total } \\
\text { Subtotal }\end{array}$ & $\begin{array}{l}96(84.2) \\
18(15.8) \\
\end{array}$ & $\begin{array}{c}34(89.5) \\
4(10.5) \\
\end{array}$ & $\begin{array}{c}33(86.8) \\
5(13.2) \\
\end{array}$ & $\begin{array}{c}29(76.3) \\
9(23.7) \\
\end{array}$ & \\
\hline $\begin{array}{l}\text { Surgical intervention } \\
\text { time, min., mean (SD) }\end{array}$ & $58.46(25.85)$ & $61.03 \pm 28.47$ & $61.18 \pm 24.63$ & $53.16 \pm 24.12$ & $1.202 / 0.31^{*}$ \\
\hline
\end{tabular}

The patients in the supine $0^{\circ}, 30^{\circ}$ and $45^{\circ} \mathrm{HOBE}$ groups were similar in terms of the descriptive characteristics including age, gender, body mass index (BMI), diagnosis, type of thyroidectomy and surgical intervention time $(\mathrm{p}>0.05$; Table 1$)$.

\section{Effect of positions on outcome measures Primary outcomes}

Respiratory rate was between 16 and 20 breaths per minute in all the patients. In the comparison between the groups, the mean RR (18.47; 95\% CI, 17.85-19.09) of the patients in the supine $30^{\circ} \mathrm{HOBE}$ group at $1 \mathrm{st}$ hour was significantly higher than that of the patients in the supine $0^{\circ}$ group (17.32; 95\% CI, 16.88-17.76) $(\mathrm{p}=0.01$, Table 2$)$.

In the in-group comparison according to the repeated measurements, the mean RR of the supine $0^{\circ}$ group at the $4^{\text {th }}$ hour $(16.89 ; 95 \%$ CI, 16.53-17.26) was significantly lower than that at the $2^{\text {nd }}$ hour $(17.53 ; 95 \%$ CI, 17.08-17.97) ( $\mathrm{p}=0.03$, Table 2). The mean RR in the supine $30^{\circ} \mathrm{HOBE}$ group at the $1^{\text {st }}$ hour $(18.47$; 95\% CI,
17.85-19.09) was significantly higher than the measurements at the $2^{\text {nd }}, 3^{\text {rd }}$ and $4^{\text {th }}$ hours $(p=<0.001$, Table 2$)$. The mean RR of the patients in the supine 450 HOBE group at the 1 st hour $(17.95 ; 95 \%$ CI, 17.39-18.51) was significantly higher than that at the 3rd hour (17.21; 95\% CI, 16.74-17.68) ( $\mathrm{p}=0.009$, Table 2). SpO2 values of all the patients were $>95 \%$ and there was no significant difference between and within the groups $(\mathrm{p}>0.05$, Table 2).

The amount of drainage was significantly higher in the supine $0^{\circ}$ group at $2^{\text {nd }}$ hour $(5.92 \pm 5.18)$ than that of the patients in the supine $45^{\circ} \mathrm{HOBE}$ group (3.34 \pm 5.56$)$ $(p=0.01$, Table 2$)$. According to the repeated measurements within the group, the amount of drainage decreased significantly at the $2^{\text {nd }}, 3^{\text {rd }}$ and $4^{\text {th }}$ hours in all the groups compared to the 1 st hour $(\mathrm{p}<0.001$, Table 2$)$. In addition, the amount of drainage of the patients in the supine $30^{\circ} \mathrm{HOBE}$ group at the $3^{\text {rd }}$ and $4^{\text {th }}$ hours was significantly lower than that at the $2^{\text {nd }}$ hour $(p<0.001$, Table 2). Moreover, the amount of drainage decreased in other groups at the $4^{\text {th }}$ hour whereas there was an insignificant increase in the supine $0^{\circ}$ group (Table 2 ). 
Table 2: The effect of positions on primary outcomes of patients

\begin{tabular}{|c|c|c|c|c|c|c|c|c|}
\hline \multirow{2}{*}{$\begin{array}{l}\text { Evaluation } \\
\text { Time }\end{array}$} & \multicolumn{2}{|c|}{ Supine $0^{\circ}$ Group $^{1}(n=38)$} & \multirow{2}{*}{$\begin{array}{l}\begin{array}{l}\text { Supine } 30^{\circ} \\
(\mathrm{n}=38)\end{array} \\
\text { Mean } \pm \text { SD } \\
\end{array}$} & \multirow{2}{*}{$\begin{array}{c}\text { HOBE Group }{ }^{2} \\
95 \% \mathrm{CI}\end{array}$} & \multicolumn{2}{|c|}{$\begin{array}{l}\text { Supine } 45^{\circ} \text { HOBE } \\
\operatorname{Group}^{3}(n=38)\end{array}$} & \multirow{2}{*}{$F / p^{*}$} & \multirow{2}{*}{ Difference } \\
\hline & Mean \pm SD & $95 \%$ CI & & & $\operatorname{Mean} \pm$ SD & $95 \% \mathrm{CI}$ & & \\
\hline \multicolumn{9}{|c|}{ Respiratory rate } \\
\hline 1st hour ${ }^{\text {a }}$ & $17.32 \pm 1.34$ & $16.88-17.76$ & $18.47 \pm 1.89$ & $17.85-19.09$ & $17.95 \pm 1.71$ & $17.39-18.51$ & $4.639 / 0.01$ & \multirow[t]{6}{*}{$1<2$} \\
\hline 2nd hour ${ }^{b}$ & $17.53 \pm 1.35$ & $17.08-17.97$ & $17.89 \pm 1.86$ & $17.28-18.51$ & $17.68 \pm 1.89$ & $17.06-18.31$ & $0.44 / 0.65$ & \\
\hline 3 rd hour ${ }^{c}$ & $17.37 \pm 1.15$ & $16.99-17.75$ & $17.63 \pm 1.91$ & $17.00-18.26$ & $17.21 \pm 1.44$ & $16.74-17.68$ & $0.734 / 0.48$ & \\
\hline 4 th hour ${ }^{d}$ & $16.89 \pm 1.11$ & $16.53-17.26$ & $17.47 \pm 1.66$ & $16.93-18.02$ & $17.37 \pm 1.48$ & $16.88-17.85$ & $1.760 / 0.18$ & \\
\hline $\mathbf{F} / \mathbf{p}^{\dagger}$ & $2.986 / \mathbf{0 . 0 3}$ & & $6.783 /<0.001$ & & $4.080 / 0.009$ & & & \\
\hline Difference & $\mathbf{d}<\mathbf{b}$ & & $\mathbf{b}, \mathbf{c}, \mathbf{d}<\mathbf{a}$ & & $\mathbf{c}<\mathbf{a}$ & & & \\
\hline \multicolumn{9}{|c|}{ Peripheral oxygen saturation } \\
\hline 1st hour ${ }^{\mathrm{a}}$ & $96.29+2.51$ & $95.46-97.12$ & $95.95+2.60$ & $95.09-96.80$ & $96.24+1.95$ & $95.60-96.88$ & $0.229 / 0.80$ & \\
\hline 2nd hour ${ }^{b}$ & $96.55 \pm 2.09$ & $95.87-97.24$ & $95.61 \pm 2.58$ & $94.76-96.45$ & $95.89 \pm 1.67$ & $95.34-96.44$ & $1.941 / 0.15$ & \\
\hline 3 rd hour ${ }^{c}$ & $96.29+2.17$ & $95.58-97.00$ & $96.18+2.32$ & $95.42-96.95$ & $96.24+1.76$ & $95.66-96.82$ & $0.024 / 0.98$ & \\
\hline 4 th hour ${ }^{\mathrm{d}}$ & $96.21 \pm 2.30$ & $95.45-96.97$ & $96.05 \pm 2.71$ & $95.16-96.94$ & $96.11 \pm 2.04$ & $95.44-96.77$ & $0.044 / 0.96$ & \\
\hline $\mathbf{F} / \mathbf{p}^{\dagger}$ & $0.412 / 0.75$ & & $0.881 / 0.43$ & & $0.655 / 0.58$ & & & \\
\hline \multicolumn{9}{|c|}{ Amount of drainage } \\
\hline & Mean \pm SD & $\begin{array}{l}\text { Median } \\
\text { (Q1-Q3) }\end{array}$ & Mean \pm SD & $\begin{array}{l}\text { Median } \\
\text { (Q1-Q3) }\end{array}$ & Mean \pm SD & $\begin{array}{l}\text { Median } \\
\text { (Q1-Q3) }\end{array}$ & $\chi^{2} / \mathbf{p}^{\mathrm{w}}$ & \multirow{7}{*}{$3<1$} \\
\hline 1st hour ${ }^{\mathrm{a}}$ & $7.39 \pm 4.53$ & $9(3-12)$ & $8.79 \pm 8.20$ & $6(3-10.50)$ & $7.03 \pm 6.31$ & $6(0-10)$ & $0.983 / 0.61$ & \\
\hline 2 nd hour ${ }^{b}$ & $5.92+5.18$ & $6(1.5-9)$ & $5.16+4.97$ & $6(0-6.75)$ & $3.34+5.56$ & $0(0-6)$ & $8.593 / \mathbf{0 . 0 1}$ & \\
\hline $3 r d$ hour $^{c}$ & $3.61 \pm 4.00$ & $3(0-6.75)$ & $3.92 \pm 5.56$ & $3(0-6)$ & $3.76 \pm 6.12$ & $1(0-6)$ & $0.484 / 0.79$ & \\
\hline 4 th hour $^{\mathrm{d}}$ & $5.37 \pm 7.55$ & $3(0-6)$ & $3.47 \pm 4.58$ & $3(0-6)$ & $3.74 \pm 4.80$ & $3(0-6)$ & $1.439 / 0.49$ & \\
\hline$\chi^{2} / \mathrm{p} ¥$ & $20.798 /<0.001$ & & $29.582 /<0.001$ & & $31.601 /<0.001$ & & & \\
\hline Difference & $\mathbf{b}, \mathbf{c}, \mathbf{d}<\mathbf{a}$ & & $\begin{array}{c}\mathbf{b}, \mathbf{c}, \mathbf{d}<\mathbf{a} \\
\mathbf{c}, \mathbf{d}<\mathbf{b}\end{array}$ & & $\mathbf{b}, \mathbf{c}, \mathbf{d}<\mathbf{a}$ & & & \\
\hline $\begin{array}{l}\text { HOBE: head-o } \\
\text { One-way AN } \\
\text { Repeated Mer } \\
\text { "Kruskal Wall } \\
\text { Friedman's 2-way te }\end{array}$ & $\begin{array}{l}\text {-bed elevation } \\
\text { OVA } \\
\text { sures ANOVA } \\
\text { s } \mathrm{H} \text { test } \\
\text { t by ranks }\end{array}$ & & & & & & & \\
\hline
\end{tabular}

\section{Secondary outcomes}

None of the patients had hematoma formation (Figure 2). None of the patients in the supine $30^{\circ} \mathrm{HOBE}$ group had dyspnea. Nine patients in the supine $0^{\circ}$ group and 3 patients in the supine $45^{\circ} \mathrm{HOBE}$ group complained of dyspnea. The number of patients who had dyspnea at 2 nd hour $(n=3)$ and $3^{\text {rd }}$ hour $(n=4)$ was more than in the supine $0^{\circ}$ group (Figure 2$)$.

In the in-group comparison according to four different evaluation times, there was no significant difference in terms of dyspnea formation in all groups ( $p>0.05$, Figure 2).

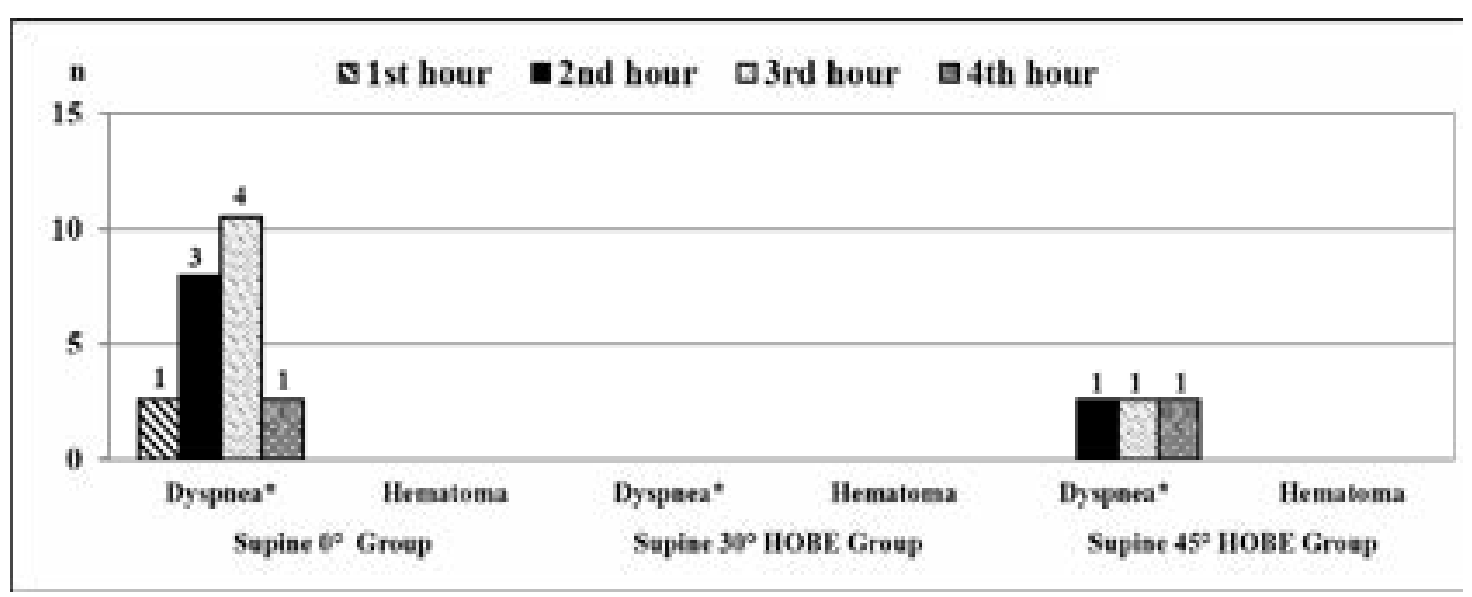

* McNemar chi-square test statistic, $\mathrm{p}>0.05$.

Figure 2: Secondary outcomes of patients 


\section{Discussion}

The findings of this study contribute to the literature by providing evidence-based information on the effect of different positions given to patients after thyroidectomy on respiratory pattern and drainage. In the study, it was determined that supine $0^{\circ}$ (baseline), $30^{\circ}$ and $45^{\circ}$ HOBE positions led to clinically insignificant differences on the RR and amount of drainage but did not affect $\mathrm{SpO}_{2}$ value.

The normal RR interval for a healthy adult without breathing problems is $12-20$ breaths per minute. ${ }^{27}$ In this study, the RR of patients who were given supine $0^{\circ}$ position at the 1 st hour after thyroidectomy was significantly lower than those given $30^{\circ} \mathrm{HOBE}$. However, this decrease was not clinically significant since all patients in the groups had a normal interval of RR (16-20 breaths per minute). In addition, statistically significant but clinically insignificant differences in RR values were determined in the repeated measurements within the group. On the other hand, there are currently no studies in the literature researching the effects of position on RR following thyroidectomy. The existing studies focus on the effect of $\mathrm{HOBE}$ and supine $0^{\circ}$ positions on lung function such as functional residual capacity and vital capacity. In one of these studies, supine $30^{\circ} \mathrm{HOBE}$ was found to increase lung volume compared to supine $0^{\circ}$ in cardiac surgery patients undergoing MV. ${ }^{16}$ Some other similar studies found that, when compared with supine $0^{\circ}, 45^{\circ} \mathrm{HOBE}$ position increased vital capacity ${ }^{20}$ and supine $0^{\circ}$ position decreased breathing frequency 2.73 breaths/min on average. ${ }^{21}$ In the current study, we did not evaluate the effect of position on lung function. However, this study was the first to examine the effect of position on RR following thyroidectomy. The fact that patients with respiratory or heart diseases were not included in the current study may have caused position not to have a clinically significant effect on the RR. The research findings and the fact that $R R$ is an independent risk factor for hospital mortality ${ }^{30}$ indicates the need for further research on the effect of patient positions on RR following thyroidectomy.

Peripheral oxygen saturation, which is recommended to be $>95 \%$ in critical care settings, is acknowledged to be the most sensitive sign of life in hospital mortality and admission to intensive care unit. ${ }^{30}$ Therefore, it is important to determine whether $\mathrm{SpO}_{2}$ is affected by the positions given to patients following thyroidectomy. In the current study, the $\mathrm{SpO}_{2}$ value of the patients was $95 \%$ or higher, and the positions did not affect the $\mathrm{SpO}_{2}$ value. There are currently no research findings showing the effect of position on $\mathrm{SpO}_{2}$ value in patients with thyroidectomy. In studies conducted with different patient groups, it was determined that supine $0^{\circ}$ and supine $30^{\circ} \mathrm{HOBE}$ positions did not have a clinically significant effect on $\mathrm{SpO}_{2}$ values in a similar way to the results of the current study. ${ }^{16,23}$ According to Benedik et al., it is difficult to detect the effect of very small changes in the partial oxygen pressure $\left(\mathrm{PO}_{2}\right)$ on $\mathrm{SpO}_{2}$ by pulse oximetry. ${ }^{23}$ Investigating the impact of these positions on oxygenation with new studies involving arterial blood gas analyzes is important since it will guide nurses to interpret small changes in $\mathrm{SpO}_{2}$.

In order to monitor $\mathrm{POH}$ and prevent hematoma in the postoperative period, many surgeons place a closed suction drain in the thyroid bed at the end of thyroidectomy. ${ }^{24,31-34}$ The nurse should closely monitor the amount of drainage $e^{5,14,26}$ because one of the first signs and symptoms of $\mathrm{POH}$ is the accumulation of more than $150 \mathrm{ml}$ per hour drainage in the suction bottle. Previous studies reported that the incidence of $\mathrm{POH}$ after thyroidectomy was $1-1.7 \%, 3,5,9,10,33$ and the incidence of hematoma causing fatal complications such as hypoxia and laryngopharyngeal edema varied in the range of $0-2.6 \% .^{2,4,8,32,35-37}$ In our study, none of the patients had POH or hematoma findings. One of the reasons may be the fact that the follow-up period was limited to 4 hours due to the mobilization of the patients after the $4^{\text {th }}$ hour following thyroidectomy in the clinic where the study was conducted. This is because unlike the evidence suggest that the initial findings of $\mathrm{POH}$ are seen within the first 4 hours after thyroidectomy, ${ }^{3}$ there are also studies reporting that excessive drainage is seen within the first $6,9,11,34$ or 8 hours ${ }^{26}$ following thyroidectomy. Similar studies showed that hematoma occurs within the first 6 hours after thyroidectomy., ${ }^{4,7}$ Another reason for the absence of hematoma and $\mathrm{POH}$ in the current study may be that the risk factors such as male $\operatorname{sex}^{2,6-8,35,37}$, thyroid cancer, ${ }^{2,3,35}$ Graves disease ${ }^{2,6,7}$ and subtotal thyroidectomy, ${ }^{2,35}$ which increase the risk of hematoma and $\mathrm{POH}$, were low in our research groups. In addition, exclusion of the patients who were using anticoagulants and whose coagulation tests were abnormal from the current study might have been effective in the absence of hematoma and $\mathrm{POH}$.

In this study, the amount of drainage of all patients in the groups decreased significantly over time compared to the first hour. However, the amount of drainage was higher in the patients in supine $0^{\circ}$ group at the $2^{\text {nd }}$ hour after thyroidectomy than in $45^{\circ} \mathrm{HOBE}$ group, which is important although not clinically significant because 
there are currently no research findings about the effect of position on the amount of drainage. As there are no valves in the veins of the head and neck, lying flat position is known to increase venous pressure and cause soft tissue edema while HOBE decreases edema. ${ }^{38}$ In the light of this, the increase in the amount of drainage in the supine $0^{\circ}$ group in our study can be attributed to the greater drainage from the thyroidectomy bed due to increased venous pressure in this position. While a decrease was observed in all the other patients, it was noteworthy that there was an insignificant increase in the amount of drainage only in the supine $0^{\circ}$ patients at the 4th hour. However, there are currently no research findings to confirm this result. Perhaps, this effect of supine $0^{\circ}$ position can be demonstrated by future studies with longer follow-up durations.

In the current study, no dyspnea occurred in any of the patients in the $30^{\circ} \mathrm{HOBE}$ group. The patients with dyspnea were in the supine $0^{\circ}(\mathrm{n}=9)$ and $45^{\circ} \mathrm{HOBE}$ $(n=3)$ groups. Previous studies reported that dyspnea was the result of hematoma-related airway compression after thyroidectomy and the incidence was 0.75 $10.3 \% ., 24,31$ In this study, dyspnea was not associated with hematoma or hemorrhage, and did not require intervention. In an observational study, risk factors such as giant goiter and malignant goiter were determined in patients experiencing respiratory problems after thyroidectomy. ${ }^{25}$ When we examined the diagnosis of our patients with dyspnea based on that study, we determined that dyspnea developed in patients with multinodular goiter and thyroid cancer. Although our groups were similar to each other in terms of diagnostic features, it was noteworthy that dyspnea occurred in more patients in the supine $0^{\circ}$ group. On the other hand, there are currently no research findings on the relationship between dyspnea formation and position after thyroidectomy. In this study, the cause of dyspnea in more patients in the supine $0^{\circ}$ position group may be due to the fact that the increase in venous pressure in this position ${ }^{38}$ may affect airway patency along with surgical surgeries caused by surgical manipulation. ${ }^{14}$

\section{Limitations}

This study has several limitations. One of the important limitations of this study is that the follow-up period was limited to 4 hours because patients due to the mobilization of the patients after the $4^{\text {th }}$ hour following thyroidectomy in the clinic where the study was conducted. The short follow-up period might have prevented us from thoroughly evaluating the effects of positions on amount of drainage and hematoma because $\mathrm{POH}$ and hematoma were found to develop within the first 6 $4,7-9,11,34$ or 8 hours $^{26}$ after thyroidectomy. The effect of the position on the amount of drainage and hematoma formation could be clearly shown by future studies with a minimum follow-up period of 8 hours. The second limitation is the inability to measure functional residual capacity (FRC) or forced vital capacity (FVC). FRC or FVC were used to determine the effect of the position on respiration in studies with different patient groups. ${ }^{16,20}$ These measurements may provide a better understanding of the effect of different positions in the study on the respiratory pattern of patients with thyroidectomy. The third limitation is the value of oxygen saturation was measured by noninvasive pulse oximetry, not by invasive arterial blood gas, which directly showed the patient's oxygen saturation. ${ }^{23}$ Lastly, we conducted the current study in single center with patients with different thyroid diseases. Previous studies found that the factors such as type of thyroid disease $e^{2,3,6,7,35}$ and type of thyroidectomy ${ }^{2,35}$ applied affected the amount of drainage, hematoma and dyspnea. Further studies with bigger samples of patients with these risk factors at different centers may provide a better understanding of the effect of position on the amount of drainage, hematoma, and dyspnea.

\section{Conclusion}

The results of this study showed that supine $0^{\circ}$ (baseline), $30^{\circ}$ and $45^{\circ} \mathrm{HOBE}$ positions given to patients during the first 4 hours after thyroidectomy did not affect the $\mathrm{SpO}_{2}$ value of the patients. In the 1 st hour, the $\mathrm{RR}$ of the patients in the supine $0^{\circ}$ group was found to be significantly lower than that of the supine $30^{\circ}$ HOBE group but this decrease was not clinically significant. None of the patients developed hematoma and no drainage was observed in any patient so much as to make us consider POH. However, at the $2^{\text {nd }}$ hour, the amount of drainage in the supine $0^{\circ}$ group was significantly higher than that of the supine $45^{\circ} \mathrm{HOBE}$ group. In addition, no patient had any dyspnea in the supine $30^{\circ} \mathrm{HOBE}$ group. Nine patients in the supine $0^{\circ}$ group and 3 patients in the supine $45^{\circ}$ HOBE group complained of dyspnea. These findings suggest that, even though American Thyroid Association recommends $45^{\circ}$-Fowler's position after thyroidectomy, the supine $0^{\circ}$ and $30^{\circ} \mathrm{HOBE}$ positions can also be given during the first 4 hours following thyroidectomy.

\section{Acknowledgement}

The statistical consultancy of this study has been provided by MedicReS, Medical Research Support, New 
York. The authors would like to thank Assoc. Prof. Yazile Sayın for her counseling in the reporting process of the study. The authors also thank the Endocrine Surgical Clinic staff and the patients who participated in the study.

\section{Conflict of interest}

None declared.

\section{References}

1. Christou N, Mathonnet M. Complications after total thyroidectomy. J Visc Surg. 2013; 150 (4): 249-256.

2. Suzuki S, Yasunaga H, Matsui H, Fushimi K, Saito Y, Yamasoba T. Factors associated with neck hematoma after thyroidectomy: A retrospective analysis using a Japanese inpatient database. Medicine (Baltimore) 2016; 95(7): e2812.

3. Zhang X, Du W, Frang Q. Risk factors for postoperative haemorrhage after total thyroidectomy: Clinical results based on 2,678 patients. Sci Rep. 2017; 7(1): 7075. 4. Al-Qahtani AS, Abouzeid Osman T. Could post-thyroidectomy bleeding be the clue to modify the concept of postoperative drainage? A prospective randomized controlled study. Asian J Surg. 2018; 41(5): 511-516.

5. Wojtczak B, Aporowicz M, Kaliszewski K, Bolanowski M. Consequences of bleeding after thyroid surgery -analysis of 7805 operations performed in a single center. Arch Med Sci. 2018; 14(2): 329-335.

6. Greenleaf EK, Goyal N, Hollenbeak CS, Boltz MM. Resource utilization associated with cervical hematoma after thyroid and parathyroid surgery. J Surg Res. 2017; 218: 67-77.

7. Campbell MJ, McCoy KL, Shen WT, Carty SE, Lubitz CC, Moalem J, et al. A multi-institutional international study of risk factors for hematoma after thyroidectomy. Surgery 2013; 154(6): 1283-1289.

8. Lang BH, Yih PC, Lo CY. A review of risk factors and timing for postoperative hematoma after thyroidectomy: is outpatient thyroidectomy really safe? World J Surg. 2012; 36(10), 2497-2502.

9. Promberger R, Ott J, Kober F, Koppitsch C, Seemann R, Freissmuth M, et al. Risk factors for postoperative bleeding after thyroid surgery. Br J Surg. 2012; 99(3): 373-379.

10. Küçükkartallar T, Tekin A, Kartal A. Importance of hemostasis at trendelenburg position in order to prevent bleedings after thyroidectomy and evaluation of 17 bleeding among 1650 thyroidectomies. Turkiye Klinikleri Journal of Endocrinology Special Topics 2010; 5(2): 49-53.

11. Terris DJ, Snyder S, Carneiro-Pla D, Inabnet WB 3rd, Kandil E, et al. American Thyroid Association
Statement on outpatient thyroidectomy. Thyroid. 2013; 23(10): 1193-1202.

12. Tokaç M, Dumlu EG, Bozkurt B, Öcal H, Aydın C, Yalçın, A, et al. Effect of intraoperative valsalva maneuver application on bleeding point detection and postoperative drainage after thyroidectomy surgeries. Int Surg. 2015; 100(6): 994-998.

13. Woods RS, Woods JF, Duignan ES, Timon C. Systematic review and meta-analysis of wound drains after thyroid surgery. BrJ Surg. 2014; 101(5): 445-456.

14. Furtado L. Thyroidectomy: Post-operative care and common complications. Nursing Stand. 2011; 25(34): 4352.

15. Lan CC, Chang CY, Peng CK, Wu CP, Huang KL, Lee SC, et al. Effect of body positions on hemodynamics and gas exchange in anesthetized pigs shortly after pneumonectomy. Shock. 2010; 34(5): 482-487.

16. Spooner AJ, Corley A, Sharpe NA, Barnett AG, Caruana LR, Hammond NE, et al. Head-of-bed elevation improves end-expiratory lung volumes in mechanically ventilated subjects: A prospective observational study. Respir Care. 2014; 59(10): 1583-1589.

17. Martinez BP, Silva JR, Silva VS, Gomes Neto M, Forgiarini Júnior LA. Influence of different body positions in vital capacity in patients on postoperative upper abdominal. Braz J Anesthesiol. 2015; 65(3): 217-221.

18. Cicolini G, Pizzi C, Palma E, Bucci M, Schioppa F, Mezzetti A, et al. Differences in blood pressure by body position (supine, fowler's, and sitting) in hypertensive subjects. Am J Hypertens. 2011; 24(10): 1073-1079.

19. Hignett R, Fernando R, McGlennan A, McDonald $\mathrm{S}$, Stewart A, Columb M, et al. A randomized crossover study to determine the effect of a $30^{\circ}$ head-up versus a supine position on the functional residual capacity of term parturients. Anesth Analg. 2011; 113(5): 1098-1102. 20. Kumar Pal A, Tiwari S, Kumar Verma D. Spirometric measurements of obese and non-obese subjects in recumbent body positions. IJCMR. 2018; 5(6): F1-F3.

21. Riera J, Pérez P, Cortés J, Roca O, Masclans JR, Rello J. Effect of high-flow nasal cannula and body position on end-expiratory lung volume: A cohort study using electrical impedance tomography. Respir Care. 2013; 58(4): 589-596.

22. Kumrow D, Dahlen R. Thyroidectomy: Understanding the potential for complications. Medsurg Nurs. 2002; 11(5): 228-235.

23. Benedik PS, Baun MM, Keus L, Jimenez C, Morice $\mathrm{R}$, Bidani A, et al. Effects of body position on resting lung volume in overweight and mildly to moderately obese subjects. Respir Care. 2009; 54(3): 334-339.

24. Memon ZA, Ahmed G, Khan SR, Khalid M, Sultan 
N. Postoperative use of drain in thyroidlobectomy - a randomized clinical trial conducted at Civil Hospital, Karachi, Pakistan. Thyroid Res. 2012; 5(1):9.

25. Rahman GA. Possible risk factors for respiratory complications after thyroidectomy: An observational study. Ear, Nose Throat J. 2009; 88(4): 890-892.

26. Amir I, Morar P, Belloso A. Postoperative drainage in head and neck surgery. Ann R Coll Surg Engl. 2010; 92(8): 651-654.

27. Flenady T, Dwyer T, Applegarth J. Accurate respiratory rates count: So should you! Australas Emerg Nurs J. 2017; 20(1): 45-47.

28. American Thoracic Society. Dyspnea: Mechanisms, assessment, and management. A consensus statement. Am J Respir Crit Care Med. 1999; 159 (1): 321-340.

29. Norman GR, Sloan JA, Wyrwich KW. Interpretation of changes in health-related quality of life: the remarkable universality of half a standard deviation. Med Care. 2003; 41(5): 582-592.

30. Barfod C, Lauritzen MM, Danker JK, Sölétormos G, Forberg JL, Berlac PA, et al. Abnormal vital signs are strong predictors for intensive care unit admission and in-hospital mortality in adults triaged in the emergency department - a prospective cohort study. Scand J Trauma Resusc Emerg Med. 2012; 20: 28.

31. Deveci U, Altintoprak F, Sertan Kapakli M, Manukyan MN, Cubuk R, Yener N, et al. Is the use of a drain for thyroid surgery realistic? A prospective randomized interventional study. J Thyroid Res. 2013; 2013:285768.

32. Duman K, Çetin B, Yiğit G, Erem HH. Dren kullanmadan gerçekleştirdiğimiz tiroidektomi olgularının geriye dönük analizi: tiroidektomilerde rutin olarak dren kullanılması gerçekten gerekli mi? Gülhane T⿰p Dergisi 2014; 56: 143-146.

33. Schietroma M, Pessia B, Bianchi Z, De Vita F, Carlei F, Guadagni S, et al. Thyroid surgery: to drain or not to drain, that is the problem -a randomized clinical trial. ORL J Otorbinolaryngol Relat Spec. 2017; 79(4): 202-211. 34. Minami S, Sakimura C, Hayashida N, Yamanouchi $\mathrm{K}$, Kuroki T, Eguchi S. Timing of drainage tube removal after thyroid surgery: a retrospective study. Surg Today 2014; 44(1): 137-141.

35. Morton RP, Vandal AC. Postoperative systolic blood pressure as a risk factor for haematoma following thyroid surgery. Clin Otolaryngol. 2015; 40(5): 462-467.

36. Weiss A, Lee KC, Brumund K'T, Chang DC, Bouvet M. Risk factors for hematoma after thyroidectomy: results from the nationwide inpatient sample. Surgery 2014; 156(2): 399-404.

37. Talutis SD, Drake FT, Sachs T, Rao SR, McAneny D. Evacuation of postoperative hematomas after thyroid and parathyroid surgery: An analysis of the CESQIP Database. Surgery. 2019; 165(1): 250-256.

38. Mickelson SA. Preoperative and postoperative management of obstructive sleep apnea patients. Otolaryngol Clin North Am. 2007; 40(4): 877-889 